\title{
Rock slope stability analysis by approximation of geological strength index and finite element method
}

\author{
Soewignjo Agus Nugroho ${ }^{1 *}$, Muhamad Yusa $^{1}$, and Andarsin Ongko ${ }^{1}$ \\ ${ }^{1}$ Department of Civil Engineering, Universitas Riau, Pekanbaru, Indonesia
}

\begin{abstract}
As a part of natural geography systems, rock slopes have treasured amount of natural resources potential. The rock materials could be utilized to fulfill several needs, especially to construct buildings. However, society sometimes have taken advantages from the slope's existence in wrong ways. The exploitations toward rock materials, either through manual or modern way (blasting) have caused some cracks occurred. These cracks have reduced the stability of rock slopes and easily triggered failures on rock slopes. In this paper, the stability of a rock slope will be precisely discussed by using Geological Strength Index (GSI) and was analyzed by using finite element method. The rock samples were taken from Pangkalan (West Sumatera, Indonesia), which this location is also vulnerable to rock slope failures. Geological Strength Index was obtained by doing manual observations on rock sample's properties, i.e. joint, cracks, and discontinuity. The result was consisted of rock's properties. Meanwhile, the analysis by using finite element method produced an outcome in form of safety factor. This result could be made as a reference for pre-disaster mitigation in Pangkalan.
\end{abstract}

\section{Introduction}

As human beings, people require a place for living. In order to fulfill that needs, people always have to keep exploring and seeking some natural resources which could be utilized as building materials. One of those materials is rocks. Rock slopes are an example of the source of natural materials which kept the amount of rock material stocks. As for the society who live in mountains area or high ground surroundings, these materials are easily found and accessed.

However, as the time passed by, society`s habits by keep exploiting natural rocks in wrong ways could have caused the failure on rocky slopes. These habits consisted of manual mining and modern exploitations (blasting method). These methods are practically dangerous and delivered huge impacts to the environments, but often neglected by people who still lack knowledge about rock slope`s condition.

\footnotetext{
*Corresponding author: nugroho.sa@eng.unri.ac.id
} 
Through exploitation and blasting method, could have caused some cracks occurred on rocks. Moreover, the cracks would get deepen. These cracks really need to be paid attention for, due to its potential in creating landslides risks [1]. These cracks created a water line and decreased the deformation modulus of rocks. Even though, according to [2], deformation modulus is a very significant parameter to measure the strength of rocks in rock sciences. Aside from the modulus, water condition is very influential in the discontinuity or rocks [3]. During the rainy season, water would have kept filling the voids inside of the rocks. This condition led to the cracks of rocks and triggered some failures on rocky slopes.

\section{Literature review}

There are some methods to determine the strength of rocks, i.e.:

\subsection{Uniaxial Compressive Strength (UCS)}

This parameter represents strength of the rock. A simple test by giving compression or load on the rock would be brought the results out. [4] has classified rocks according to their UCS results and modulus ratio. If the UCS gets higher, it will place the rock into a higher class.

\subsection{Rock Quality Designation (RQD)}

This method compared the up than $10 \mathrm{~cm}$ intact core of bor length to the length of total samples/ core run. This method has also considered the rate of rock coarseness in accessing rocks. If the rate gets higher, it represents the coarser physical properties of the rock. [5] have used this method to analyze rock characteristic in Kalan, West Kalimantan. As for [6], has used this method to access a rock slope in East Kalimantan. Same goes for [7] has applied the RQD results in South Kalimantan. In the different country state, [8] has stated this method can predict the rock`s compressive strength.

\subsection{Geological Strength Index (GSI)}

This method could be easily done by visually observing the rocks. The superiority of this method needs less time in producing accurate results. The method goes with simply observing cracks on the surface of rocks. The number of scratches will reduce the strength of the rocks. Marinos and Hoek [9] have mentioned that GSI could be utilized to evaluate the strength of rocks and it also goes along with RQD results in obtaining the rate of RMR (Rock Mass Rating). With same theory, Singh and Tamrakar [10] have used RMR and GSI to analyze rocks at the side of Malekhu River, near to Himalaya.

In this research, the evaluation of rocks was oriented to the value of GSI. The evaluation consisted of observations toward the rocks, especially on some joints and discontinuities. The results of the evaluation will be set as preliminary data and will be analyzed by using the finite element method.

Finite element method is a useful method in modeling such complicated geometry shapes of the slope. This method will split the complicated shapes and turn them become more simple shapes. The result of modeling is also easily analyzed to obtain the safety factor from the observed slope. 


\section{Research methodology}

\subsection{Materials and procedures}

In this research, the rock materials were taken from Pangkalan (West Sumatera). This location is also vulnerable to the phenomenon of landslides due to the number of slopes and weather shift. Then, the samples were properly observed to obtain the value of GSI. For accuracy, the observations were done on at least 20 points of this slope.

Next, the value of GSI will be averaged. The specific kinds of cracks and its GSI score could be seen in Fig. 1.

\begin{tabular}{|c|c|c|c|c|c|c|}
\hline $\begin{array}{l}\text { GEOLOGICAL STRENGTH } \\
\text { INDEX (GSI) FOR JOINTED } \\
\text { ROCKS } \\
\text { (Hoek and Marinos, 2000) }\end{array}$ & \multirow[t]{2}{*}{ 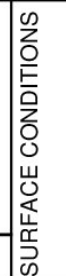 } & 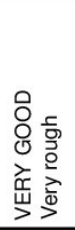 & 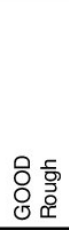 & 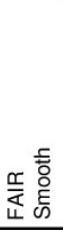 & 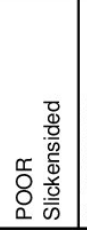 & 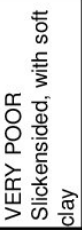 \\
\hline STRUCTURE & & \multicolumn{5}{|c|}{ DECREASING SURFACE QUALITY } \\
\hline INTACT OR MASSIVE & 岂 & & & & & \\
\hline $\begin{array}{l}\text { BLOCKY } \\
\text { well interlocked undisturbed rock } \\
\text { mass }\end{array}$ & 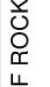 & & & & & \\
\hline $\begin{array}{l}\text { VERY BLOCKY } \\
\text { interlocked, angular blocks formed } \\
\text { by } 4 \text { or more joint sets }\end{array}$ & $\sum_{\substack{0 \\
0}}^{0}$ & & & & & \\
\hline $\begin{array}{l}\text { BLOCKY / DISTURBED / SEAMY } \\
\text { angular blocks formed by many } \\
\text { intersecting discontinuity sets }\end{array}$ & 氶 & & & & & \\
\hline $\begin{array}{l}\text { DISINTEGRATED } \\
\text { heavily broken rock mass }\end{array}$ & $\frac{\bar{c}}{\omega}$ & & & & 20 & \\
\hline $\begin{array}{l}\text { LAMINATED / SHEARED } \\
\text { close spacing of weak } \\
\text { schistosity or shear planes }\end{array}$ & - & & & & & \\
\hline
\end{tabular}

Fig. 1. Geological strength index method [11].

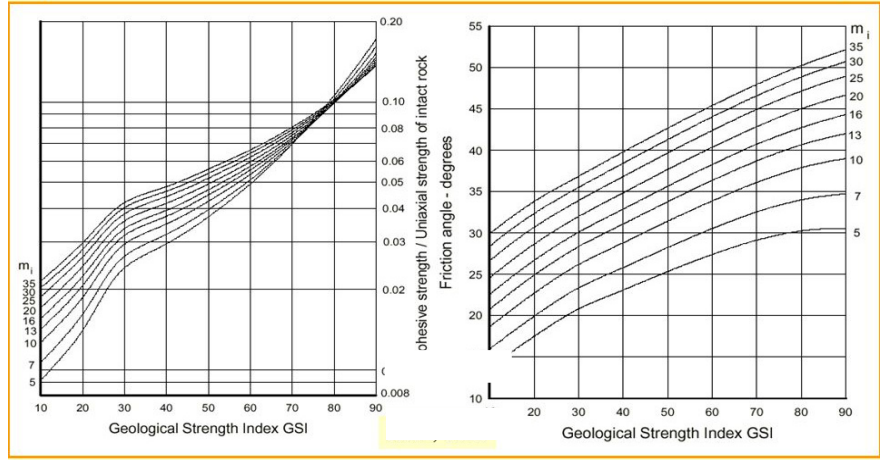

(a)

(b)

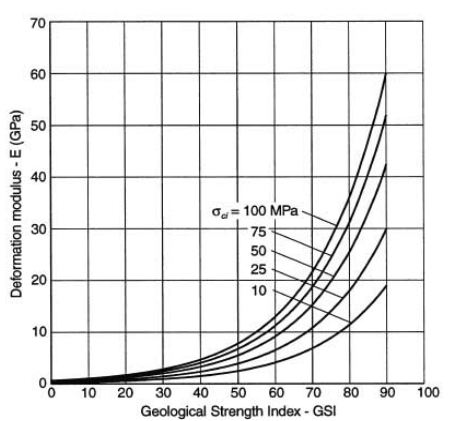

(c)

Fig. 2. (a) Value of GSI and correlation to cohesive strength [11], (b) Value of GSI and correlation to internal friction angle [11] (c) Value of GSI and deformation modulus [12]. 
As for the approximation of cohesion, internal friction angle, and deformation modulus of rock, [9] have stated about some correlations between GSI and those variables. The graphs which presented their correlations could be observed in Fig. 2 (a), (b), and (c). The deformation modulus of rock and its correlation to GSI value could be written as Eq. 1:

$$
E_{M}=0.1451 e^{0.0654 \mathrm{GSI}}
$$

\subsection{Finite Element Method}

The simple geometry of the slope could be easily modeled by using finite element method. Prior the modeling, the dimension of slope (height and steepness) need to be manually measured. The asymmetry slope model could be assumed as symmetry model for further analysis. The results will be considered as approximation value and represent the actual results.

\section{Results and discussion}

The value of GSI and samples illustration are presented in Fig. 3 and Fig. 4.

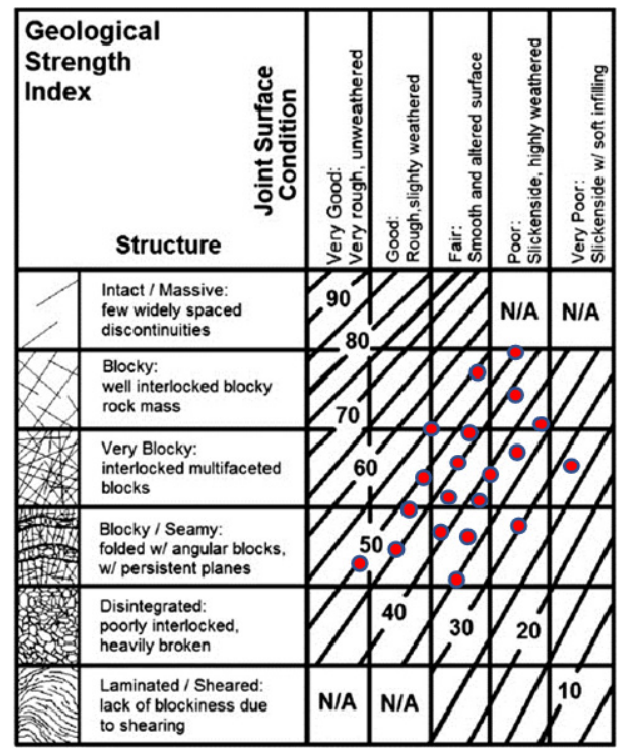

Fig. 3. Results of GSI according to field observation on Pangkalan, West Sumatera.
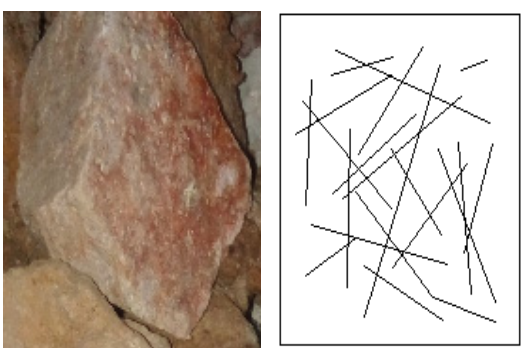

Fig. 4. Samples ilustration (a), and cracks observation (b). 
For numerical approach, the magnitude of GSI value was mentioned in Table 1.

Table 1. Numerical approach of GSI (Pangkalan Samples).

\begin{tabular}{|c|c|c|c|}
\hline No & GSI & No & GSI \\
\hline 1 & 45 & 11 & 34 \\
\hline 2 & 54 & 12 & 38 \\
\hline 3 & 42 & 13 & 36 \\
\hline 4 & 37 & 14 & 44 \\
\hline 5 & 54 & 15 & 47 \\
\hline 6 & 38 & 16 & 41 \\
\hline 7 & 26 & 17 & 39 \\
\hline 8 & 45 & 18 & 42 \\
\hline 9 & 36 & 19 & 46 \\
\hline 10 & 29 & 20 & 49 \\
\hline
\end{tabular}

The results have shown that the GSI for Pangkalan slope was about 26 to 54 in range of blocky to very blocky status. The average of GSI from 20 points of observations was 41.1, and it was classified as blocky structure rocks.

As for the real condition of the slope, its height and steepness need to be measured. The actual condition and modeled slope could be observed in Fig. 5 (a) and (b):

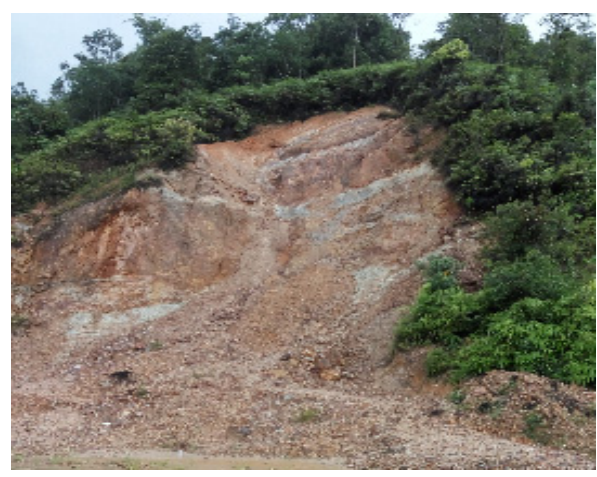

(a)

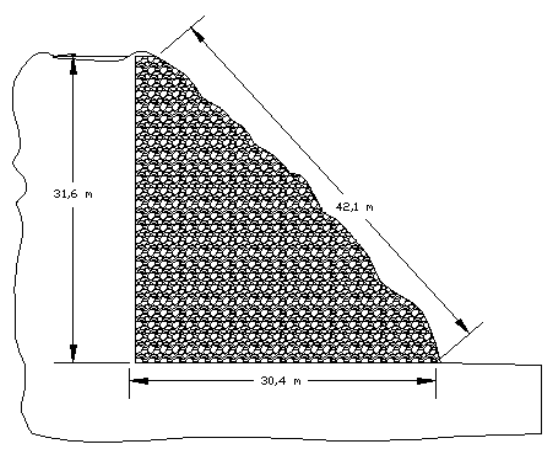

(b)

Fig. 5. (a) Slope`s real condition (b) Value of GSI and correlation to internal friction angle.

After GSI was obtained, the properties of rocks were measured as on Table 2. The properties data of rocks are next to be made as input data on finite element method. Afterward, the analysis was made according to its concern due to the weather shift. The analysis consisted of two main problems, i.e., during the dry season and wet (rainy) season.

According to Fig. 6, during the dry season, the rocks practically get harden since the percentage of water is decreased. The role of water could have caused the cohesion between each rock particle gets weaken and producing low effective stress on rocks. Vice versa, on 
the rainy season, the water filled the void inside of the rocks, which could lead this condition to failures. The results of rainy season analysis could be observed in Fig. 7.

Table 2. Properties of rocks.

\begin{tabular}{|c|c|}
\hline Properties & Results \\
\hline$\gamma$ saturated & $17.58 \mathrm{kN} / \mathrm{m}^{3}$ \\
\hline E (Deformation Modulus) & $2.133 \times 10^{6} \mathrm{kN} / \mathrm{m}^{2}$ \\
\hline$v$ (Poisson Ratio) & 0.35 \\
\hline G (Shear Modulus) & $761785.7 \mathrm{kN} / \mathrm{m}^{2}$ \\
\hline Cohesion & $1 \mathrm{MPa}$ \\
\hline Internal Friction Angle & $13.5^{\circ}$ \\
\hline
\end{tabular}

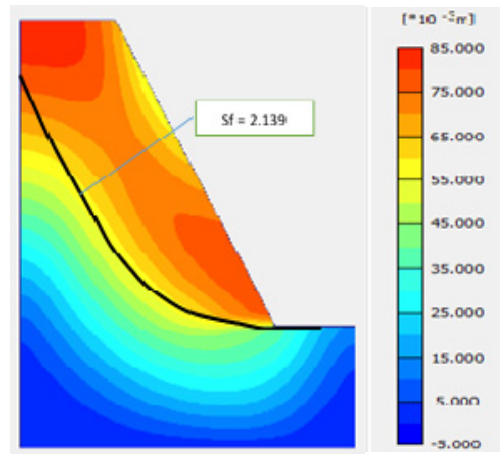

Fig. 6. Slope condition and Safety Factor during the dry season.

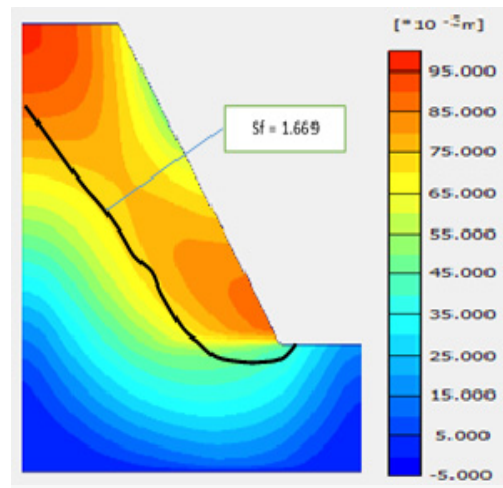

Fig. 7. Slope condition and Safety Factor during the rainy season.

Based on finite element method analysis results, the groundwater table will rise during the rainy season, especially on some cases of intense rainfall which is the main reason of the lower safety factor compared to the dry season. 
The safety factor on rainy season and dry season are respectively 1.669 and 2.139 . As for the total displacement on rainy season and dry season are respectively $95.43 \times 10^{-3} \mathrm{~m}$ and $83.6 \times 10^{-3} \mathrm{~m}$. Despite these results, the slope can still be categorized as safe.

As for the rocks properties, the physical properties of rocks could be categorized as in good condition. However, the evaluation of GSI value has shown that there were numbers of cracks which need to be considered as a natural hazard threat in the future.

\section{Conclusions}

Based on the study on Pangkalan (West Sumatera), some conclusions were taken. GSI method is very convenient to be used to produce a fast estimation of slope strength. The observed slope is still can be categorized as safe. This was proven by its safety factor, i.e., still up to 1.00. To maintain the stability of the slope, the exploitation actions need to be reduced because those actions are the main reason for the low GSI (Geological Strength Index).

\section{References}

1. T. Vondráčková, M. Myslivečková, V. Nývlt, A. Király, World Multidisciplinary Earth Sciences Symposium 15 (2015)

2. S. Panthee, P.K. Singh, A. Kainthola, R. Das, T.N. Singh, Bulletin of Engineering Geology and the Environment 77, 5 (2018)

3. S. Dochez, F. Laouafa, C. Franck, S. Guedon, F. Martineau, M. Bost, J.D`Amato, Proc. of the 14th International Symposium on Water Rock Interaction 7 (2013)

4. Palmström, In situ characterization of rocks (Balkema Publishers, Lisse, 2001)

5. H. Syaeful, D. Kamajati, Jurnal Eksplorium 36 (2015)

6. Sujiman, Jurnal Bumi Lestari 16 (2016)

7. G.W. Swana, D. Muslim, I. Sophian, Buletin Sumber Daya Geologi 7 (2012)

8. L. Zhang, Intl. J. of Rock Mechanics and Geotechnical Eng. 8 (2016)

9. P. Marinos, E. Hoek, Proc. of the GeoEng2000 (2000)

10. J.L. Singh, N.K Tamrakar, Bulletin of the Department of Geology 16 (2013)

11. E. Hoek, E.T. Brown, Int. J. of Rock Mechanics and Mining Sci. 34, 8 (1997)

12. E. Hoek, P.K. Kaiser, W.F. Bawden. Support of underground excavations in hard rock (Balkema, Amsterdam, 1995) 